\title{
ENVIRONMENTAL CONSTRAINTS ON WEST ANTARCTIC ICE-SHEET FORMATION
}

\author{
By D.R. Lindstrom and D.R. MACAYEAL
}

(Department of Geophysical Sciences, University of Chicago, Chicago, Illinois 60637, U.S.A.)

ABSTRACT. Small perturbations in Antarctic environmental conditions can culminate in the demise of the Antarctic ice sheet's western sector. This may have happened during the last interglacial period, and could recur within the next millennium due to atmospheric warming from trace gas and $\mathrm{CO}_{2}$ increases. In this study, we investigate the importance of sea-level, accumulation rate, and ice influx from the East Antarctic ice sheet in the re-establishment of the West Antarctic ice sheet from a thin cover using a time-dependent numerical ice-shelf model. Our results show that a precursor to the West Antarctic ice sheet can form within 3000 years. Sea-level lowering caused by ice-sheet development in the Northern Hemisphere has the greatest environmental influence. Under favorable conditions, ice grounding occurs over all parts of the West Antarctic ice sheet except up-stream of Thwaites Glacier and in the Ross Sea region.

\section{INTRODUCTION}

Conditions necessary for large-scale ice-sheet formation during Pleistocene glacial periods are not well documented because deep-sea and terrestrial records lack directly relevant atmospheric, oceanic, and geodynamic variables. It is difficult to envision, for example, how subtle changes in solar-radiation distribution culminates in the formation of ice sheets $3-4 \mathrm{~km}$ thick in $10 \mathrm{ka}$. Perhaps the most perplexing element of ice-sheet formation concerns marine ice-sheet inception on the continental shelves of West Antarctica and northern Eurasia (Denton and Hughes, 1981). Marine ice sheets are grounded on sub-sea-level platforms and must maintain sufficient thickness to avoid floating and losing the basal friction necessary to maintain their large mass and domed elevation profile. During inception, however, those parts of marine ice sheets which form through consolidation and thickening of a floating ice cover must do so without the advantage of basal friction. Horizontal ice divergence and iceberg calving make this initial growth far more difficult than if the ice sheet were originally situated on a land surface. The formation of a marine ice sheet can thus be characterized as a competition between divergent iceshelf flow and the ability of the atmosphere and ocean to deliver ice mass to a confined marine location.

In the present study, we examine this competition as it may have influenced the development of the present marine-based West Antarctic ice sheet. We use a timedependent numerical model which calculates ice-shelf mass balance and flow (Lindstrom and MacAyeal, 1986) to simulate the evolution of an initially thin ice cover over West Antarctica as it would appear if the present glacial load were removed and the sea bed allowed to rebound as shown in Figures 1 and 2 . The ice is floating where the isostatically adjusted bed is below sea-level and is grounded where the bed is above sea-level. Atmospheric and oceanic conditions, and ice fluxes into the West Antarctic region from adjacent ice in East Antarctica, are varied throughout a number of independent simulations. The results delimit circumstances under which parts of the initial floating ice cover will ground on the sea bed. Our study is intended to illustrate glaciological issues involved in marine ice-sheet formation as well as provide hypothetical scenarios to test should the geologic record permit.

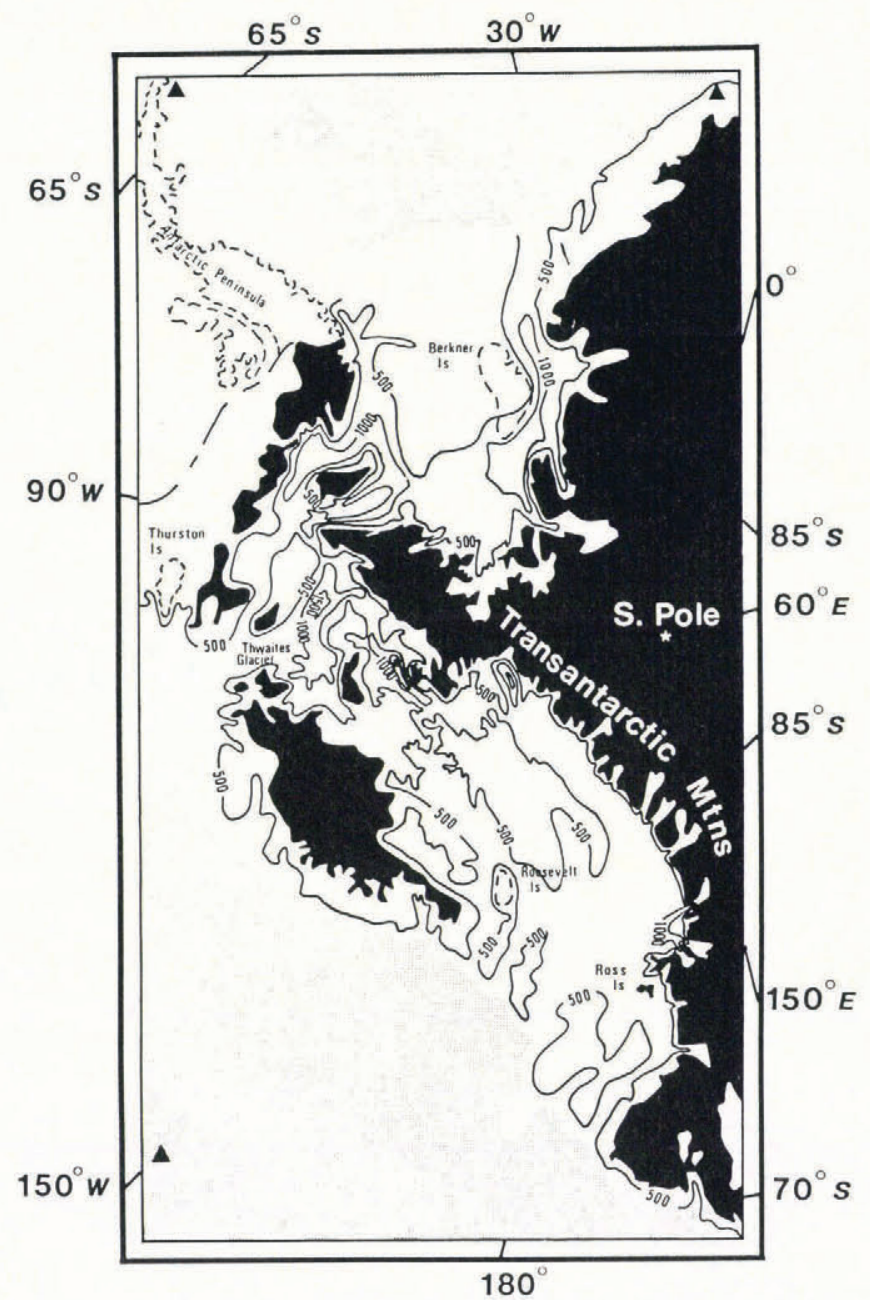

Fig. 1. Map of how West Antarctica would appear if all ice were removed and isostatic adjustment occurred (after sheet 6 of Drewry, 1983). The shaded area is beyond the continental shelf and the black area represents regions where the bed is at or above sea-level. The contoured area represents the continental region where the bed depth is below sea-level. The contour interval is $500 \mathrm{~m}$. Alternating long and short dashes represent the boundary for which inadequate bed depths have been obtained. The triangles represent the corners of the grid in Figure 2.

\section{MASS BALANCE AND WATER-BUCKET ANALOGY}

To form a marine ice sheet from a floating ice cover, more mass must be delivered to the ice cover by surface accumulation, basal freezing, and flux from adjacent ice sheets than is lost by basal melting and ice-front calving. Grounding is difficult to attain because horizontal ice velocity and mass advection through the seaward ice-front increase as the ice cover thickens. 


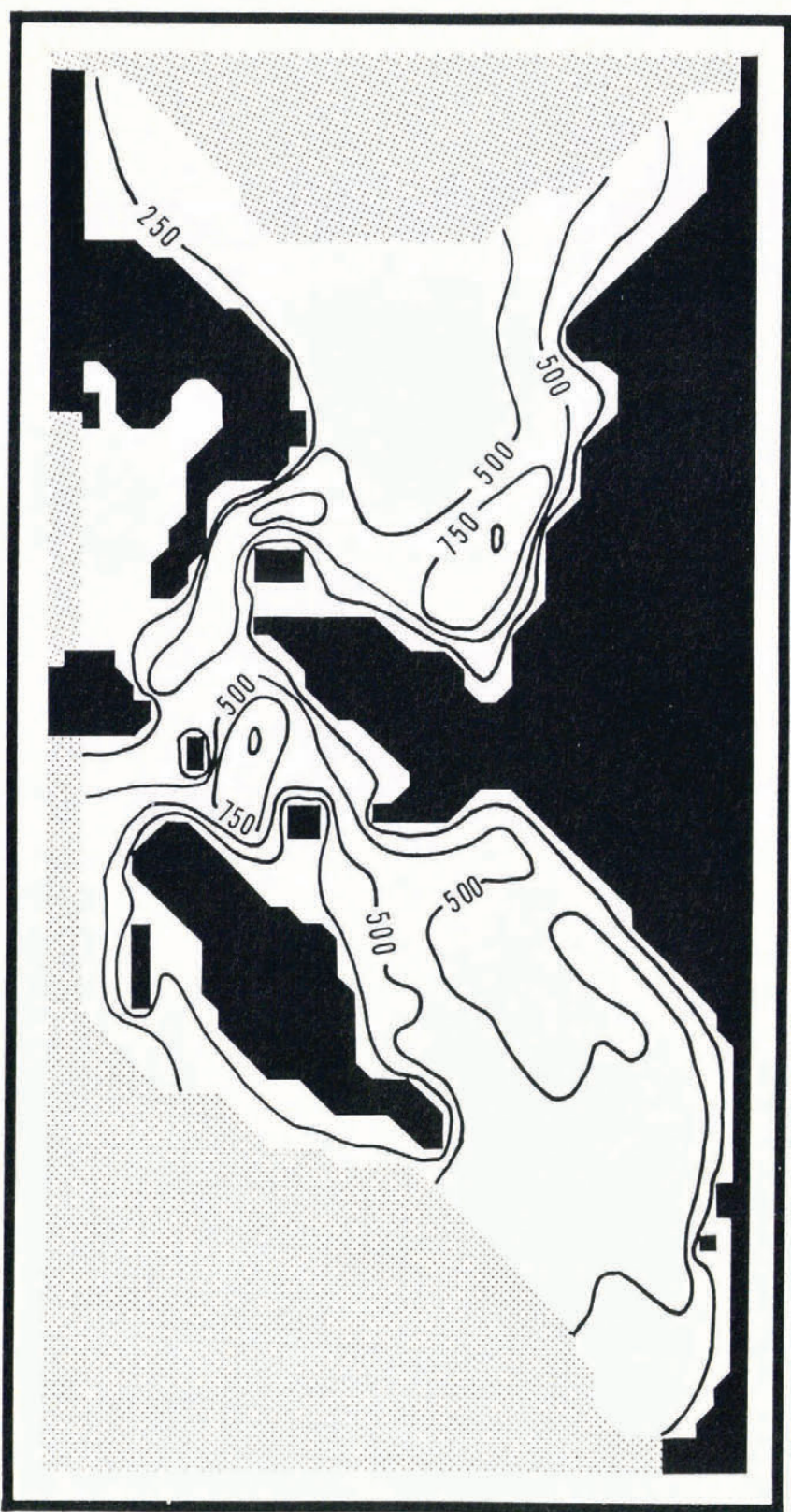

Fig. 2. Model grid representation of region depicted in Figure 1. The grid is composed of a $41 \times 83$ square element array, each element having side lengths of $50 \mathrm{~km}$. Elements on the boundary between the ice shelf and grounded ice or the sea can be divided in two along a diagonal. Symbol representations are the same as for Figure 1. Bed-depth contour interval is $250 \mathrm{~m}$.

The process is analogous to filling a leaky water bucket. If initially water is poured into the bucket faster than it leaks out, the water level will rise. As the level rises, however, the leakage rate may increase to a point balancing water input. If a balanced condition is reached before the water level reaches the top of the bucket, it will never completely fill.

The analogy between West Antarctic marine ice-sheet formation and the leaky water bucket is useful in describing geographic and glaciological factors that must be overcome for the ice cover to ground substantially. As shown in Figure 1, the West Antarctic continental shelf is configured as a channel extending from the Weddell Sea to the Ross Sea. The border with East Antarctica is mountainous. Gaps in this border allow the East Antarctic ice sheet (which presumably formed prior to the possibly multiple ice-sheet formation events in West Antarctica, but see Hughes (1982)) to spill over into the West Antarctic channel. The other side of the channel facing the South Pacific Ocean, and the two ends in the Weddell and Ross Seas, are predominantly open to the sea and would permit significant ice leakage into the ocean. One fundamental advantage the West Antarctic continental shelf has over the leaky bucket is the potential for ice grounding to plug gaps and leaks. Once the ice exceeds a critical thickness of approximately $500 \mathrm{~m}$, grounding on shallow sea-bed regions around the continental shelf's periphery reduces the net floating ice-front exposure by approximately one-half. Sealing these leaks provides the key which allows the marine ice sheet to form.

\section{METHODS OF SIMULATING WEST ANTARCTIC ICE- SHEET FORMATION}

The basic features of the finite-element model used in this study have been described by Lindstrom and MacAyeal (1986) and are summarized in the flow chart of Figure 3. Major assumptions and simplifications are listed in Table I. As indicated in the flow chart (Fig. 3), stress-equilibrium and mass-conservation equations are solved to yield the instantaneous (depth-independent) velocity distribution $\boldsymbol{u}(x, y, t)$ and the ice-thickness $H(x, y, t)$ evolution with time. The shallow ice approximation (Hutter, 1983; see also Muszynski and Birchfield, 1987) is applied to simplify stress-equilibrium conditions. Under this simplification, vertical shear stress may be disregarded and horizontal velocity may be treated as depth-independent, and the vertical stress $T_{z z}$ is glaciostatic.

The two horizontal stress-equilibrium equations may be written in terms of the horizontal velocity components and flow-law parameters using the method of weighted residuals (Lapidus and Pinder, 1982)

$\iint \bar{v}^{2}$ $\bar{v}^{z} H\{4(\partial u / \partial x)(\partial R / \partial x)+(\partial u / \partial y)(\partial R / \partial y)+(\partial v / \partial x)(\partial R / \partial y)+$

$+2(\partial v / \partial y)(\partial R / \partial x)\} \mathrm{d} x \mathrm{~d} y=$

$$
\begin{aligned}
& =\iint\left\{0.5 \rho_{\mathrm{i}} g H^{2}(\partial R / \partial x)+\left(\rho_{\mathrm{i}}{ }^{2} / \rho_{\mathrm{w}}\right) g H(\partial H / \partial x) R\right\} \mathrm{d} x \mathrm{~d} y \\
& -\int_{\Gamma} 0.5 \rho_{\mathrm{i}} g\left(\rho_{\mathrm{i}} / \rho_{\mathrm{W}}\right) H^{2} R \boldsymbol{n} \cdot \hat{e}_{x} \mathrm{~d} \lambda
\end{aligned}
$$

and

$\iint \frac{1}{v}$

$$
\begin{aligned}
& \int \bar{v}^{z} H\{4(\partial v / \partial y)(\partial S / \partial y)+(\partial v / \partial x)(\partial S / \partial x)+(\partial u / \partial y)(\partial S / \partial x)+ \\
& +2(\partial u / \partial x)(\partial S / \partial y)\} \mathrm{d} x \mathrm{~d} y= \\
& =\iint_{\left\{0.5 \rho_{\mathrm{i}} g H^{2}(\partial S / \partial y)+\left(\rho_{\mathrm{i}}{ }^{2} / \rho_{\mathrm{w}}\right) g H(\partial H / \partial y) S\right\} \mathrm{d} x \mathrm{dy}-} \\
& -\int_{\Gamma} 0.5 \rho_{\mathrm{i}} g\left(\rho_{\mathrm{i}} / \rho_{\mathrm{w}}\right) H^{2} S n \cdot \hat{e}_{y} \mathrm{~d} \lambda
\end{aligned}
$$

where $x$ and $y$ are horizontal coordinates (with $\hat{e}_{x}$ and $\hat{e}_{y}$ as unit vectors in the $x$ and $y$ directions), the domain of area integrals in the entire region of floating ice, $\Gamma$ is the ice-front contour in the horizontal plane (with outward normal $n), \quad R(x, y)$ and $S(x, y)$ are arbitrary weighting functions, $u$ and $v$ are the $x$ - and $y$-velocity components, respectively, $g$ equals $9.81 \mathrm{~m} \mathrm{~s}^{-2}, \rho_{\mathrm{i}}$ equals $917 \mathrm{~kg} \mathrm{~m}^{-3}$, and $\rho_{\mathrm{w}}$ equals $1027 \mathrm{~kg} \mathrm{~m}^{-3}$. The depth-average effective viscosity is designed to represent Glen's flow law

$$
\bar{v}^{z}(e)=\bar{B}^{z} /\left[2 e^{(1-1 / n)}\right]
$$

where $e$, the second invariant of the strain-rate tensor (simplified by the above approximations), is given by

$$
\begin{aligned}
e & =\left\{0 . 5 \left[2(\partial u / \partial x)^{2}+2(\partial v / \partial y)^{2}+2(\partial u / \partial x)(\partial v / \partial y)+\right.\right. \\
& +0.5(\partial u / \partial y+\partial v / \partial x)(\partial u / \partial y+\partial v / \partial x)]\}^{0.5} .
\end{aligned}
$$

$\bar{B}^{z}\left(\mathrm{Pas}^{1 / n}\right)$ is the proportionality between strain-rate and stress, and $n$ is the flow-law exponent taken to be 3 in this study. For simplification, we treat $\bar{B}^{z}, \rho_{\mathrm{i}}$, and $\rho_{\mathrm{w}}$ as constants. This treatment eliminates thermo-mechanical coupling and the firn layer, which can be examined in a future study. Boundary conditions applied to Equations (1) 
Topic

Spatial resolution

Bed depths

Time resolution

Isostatic adjustment of bed

Temperature-depth profile

Basal freezing rates are combined in term which specifies snow accumulation

Ice-stream dynamics

Ice density

Initial $20 \mathrm{~m}$ thick floatingice cover

Ice fracturing

\section{Comment}

The distance between adjacent grid points is $50 \mathrm{~km}$. This is adequate for representing large-scale features, but not fine enough for meso-scale features such as ice streams. Memory and run-time considerations discouraged us from working with a smaller resolution. The grid representation of the area covered by Figure 1 is shown in Figure 2

Bed depths for regions within the continental shelf that are below sea-level are estimated from sheet 6 of Drewry (1983). Contours of the bed depth are given in $500 \mathrm{~m}$ intervals in sheet 6 , so significant interpolation errors are possible. The smoothed bed-depth profile used in this study is shown in Figure 2. Bed-depth values are decreased uniformly for simulations where effects of lower sea-levels are tested

A 50 year time step is applied. Each step is $2 \%$ of the approximate 2500 years required for a steady state of mass balance to be reached

Isostatic adjustment of the bed is not treated. This is reasonable for the short time period considered in the study, and can be used as a basis for comparison in future studies where isostatic adjustment is accounted for

A linear temperature-depth profile is applied throughout. Under realistic conditions, the profile has curvature due to vertical advection, and this curvature will change with time as the ice shelf thickens. Computer memory and run-time considerations limit our ability to treat a time-dependent temperature-depth profile

Oceanic circulation patterns and temperatures during the period of ice-sheet development are not known. The model is unable to distinguish between surface-accumulation and basal freezing-rate specifications. The range of accumulation rates specified in the various simulations treats most combined effects of surface accumulation and basal freezing that are plausible

Field work is in progress to understand the dynamics and formation mechanisms of ice streams in the grounded-floating transition region of an ice-sheet system. Our model, therefore, does not treat ice-stream dynamics at this time. Our results can be used for future comparisons when ice-stream dynamics are included

Ice density is considered constant over the total ice column. This is reasonable when the ice thickness is large because the firn layer (approximately $50 \mathrm{~m}$ ) comprises a small fraction of the column

The initial emplacement of a $20 \mathrm{~m}$ thick floating-ice cover over the entire region within the continental shelf where the bed is below sea-level is completely arbitrary. No mechanism for this emplacement is given. Effects of winds and oceanic currents on the initial cover are also ignored

Ice fracturing is not treated by the model. This could be significant over the entire region, especially near ice-rise obstructions and during the first several hundred years of each simulation when the ice cover is thin and (2) are velocity (usually zero, see below) at ice-shelf/ grounded-ice junctions and stress at the seaward ice front, and sloping underside (as shown on the right-hand sides of Equations (1) and (2)).

The mass-balance equation is likewise expressed using the method of weighted residuals

$$
\begin{aligned}
& \iint H(t+\Delta t)\{P-\Delta t[u(t)(\partial P / \partial x)+v(t)(\partial P / \partial y)]\} \mathrm{d} x \mathrm{~d} y+ \\
& +\int_{\Gamma} P H(t+\Delta t) \boldsymbol{u} \cdot \boldsymbol{n} \mathrm{d} \lambda= \\
& =\iint P\{H(t)+\Delta t \AA\} \mathrm{d} x \mathrm{~d} y-\int \underset{\Gamma^{\prime}}{P Q} \cdot \boldsymbol{n}^{\prime} \mathrm{d} \lambda
\end{aligned}
$$

where $A$ is the snow-accumulation rate (basal melting is assumed zero), $\Gamma^{\prime}$ is the grounding line (with outwardpointing normal $\left.\boldsymbol{n}^{\prime}\right), \quad P(x, y)$ is an arbitrary weighting function, and $Q$ is the ice-volume flux specified at ice-shelf/grounded-ice boundaries. The second term on the left-hand side of Equation (5) specifies that flux through the ice front is to be passed freely into the ocean. This requirement assumes that the ice front $\Gamma$ remains constant in time, which is specified as shown in Figure 2. In contrast with the ice front, the grounding line $\Gamma^{\prime}$ is allowed to advance into the ice-shelf region as the simulation proceeds. This is done by designating ice-shelf elements to be grounded when their average thickness exceeds $\left[\rho_{\mathrm{w}} / \rho_{\mathrm{i}}\right] H_{\mathrm{b}}$, where $H_{\mathrm{b}}(x, y)$ is the sea-bed depth shown in 


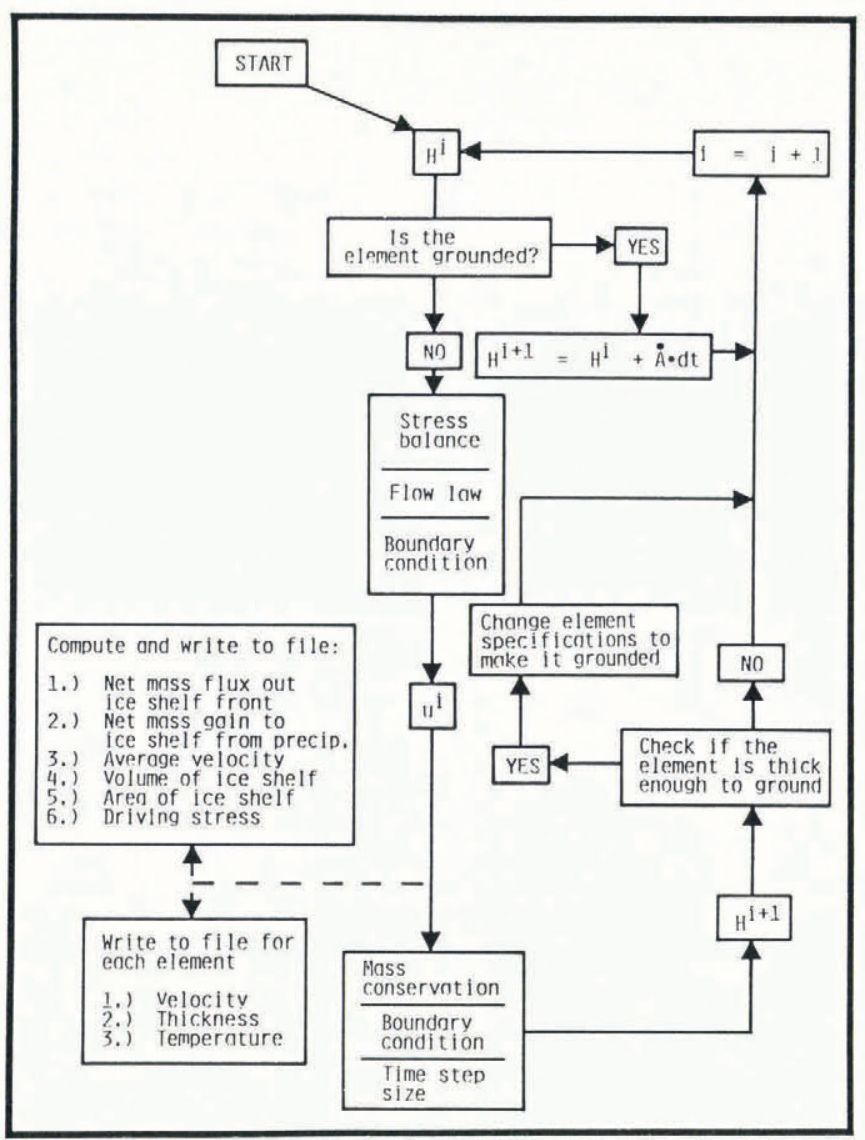

Fig. 3. Flow diagram of ice-shelf model used to analyze grounded ice-sheet initiation in this study. In the diagram, $u$ represents the depth-independent ice-velocity vector, $H$ the ice thickness, $\dot{A}$ the accumulation rate, $d t$ the time step, and $i$ the time-step number.

Figure 2. Under most simulations conducted, $Q$ is specified as zero (consistent with our assumption that grounded ice during initial stages of ice-sheet formation is stagnant). $Q$ is specified according to regional mass-balance estimates in tests where the effects of influx from East Antarctica are considered.

Ice-shelf regions that ground during the course of icesheet formation are treated as stagnant ice platforms that slowly thicken with the snow-accumulation rate. These stagnant regions initially appear as ice rises within the iceshelf domain. Their presence causes reduced seaward iceshelf flow and catalyzes further ice-shelf grounding. In tests where East Antarctic influx is specified, $Q$ is specified along those parts of the grounding line that border the East Antarctic ice sheet, but is zero along other grounding lines.

The validity of our simple treatment of grounded ice is tested by monitoring the magnitude of driving stress $\tau_{\mathrm{d}}$ over the entire grounded-ice/floating-ice domain (Whillans, 1987)

$$
\left|\tau_{\mathrm{d}}\right|=\rho_{\mathrm{i}} g H \tan \alpha
$$

where $\alpha$ is the surface slope. This test allows us to evaluate the stress level which would have driven grounded-ice flow had we chosen to treat it explicitly in our model.

Driving stress is the primary catalyst for glacial motion and is derived from gravitational forces (Whillans, 1987). Present driving-stress values for the grounded part of the West Antarctic ice sheet range from 20 to $100 \mathrm{kPa}$ (Drewry, 1983, sheet 5; Whillans, 1987). Treating grounded ice as stagnant, then, is valid so long as the driving stress remains significantly below this range (ice streams are an exception in that they flow with great speed at low driving-stress values, but they probably do not exist during the initial stages of ice-sheet formation). The areal average driving stress for the entire region originally covered by floating ice is calculated diagnostically from model output at each time step. We display the average driving stress as a function of time in Figure 4 for a number of representative simulations described below (Table II). In all simulations displayed, except those with a precipitation rate of $0.4 \mathrm{~m} \mathrm{a}^{-1}$, the driving stress remains less than $20 \mathrm{kPa}$ throughout the 3-4 ka necessary to ground the majority of the ice shelf. We conclude from this a posteriori test that grounded-ice flow dynamics, had we treated them explicitly, would have contributed little to the initial nucleation of the marine ice sheet. This conclusion does not apply to the grounded-ice dynamics that control influx from the East Antarctic ice sheet. This influx is shown by our experiments to have a significant impact on the West Antarctic ice-sheet formation. Beyond $4 \mathrm{ka}$, however, driving-stress values over grounded regions become significantly large as the ice cover thickens due to surface accumulation.

\section{MODEL EXPERIMENTS AND PARAMETER VALUES}

Twelve separate model experiments were made to test how different combinations of surface-accumulation rates, sea-level, mass input from the East Antarctic ice sheet, and $\bar{B}^{z}$ values affect West Antarctic ice-sheet formation. A summary of parameter values used for each run and the primary objective each run addresses is presented in Table II.

Realistic parameter values were specified for all runs except run number 1, which monitors development assuming non-deformable ice. Surface and basal temperatures of $-20^{\circ} \mathrm{C}$ and $-1.7^{\circ} \mathrm{C}$, respectively, were used throughout because they closely correspond to average Antarctic iceshelf surface temperatures (Budd and others, 1987, table 3) and the pressure melting-point temperature at the ice-shelf base.

The average accumulation rate over present Antarctic ice shelves is approximately $0.2 \mathrm{~m} \mathrm{a}^{-1}$ (Giovinetto and Bentley, 1985). This value was used over the entire region for most simulations. Runs were also made with accumulation rates of 0.1 and $0.4 \mathrm{~m} \mathrm{a}^{-1}$, which represent reasonable variations from different atmospheric and oceanic circulation patterns. Run number 3 investigates the effect of using a non-uniform precipitation rate over the entire region. A physically reasonable variable accumulation-rate pattern over

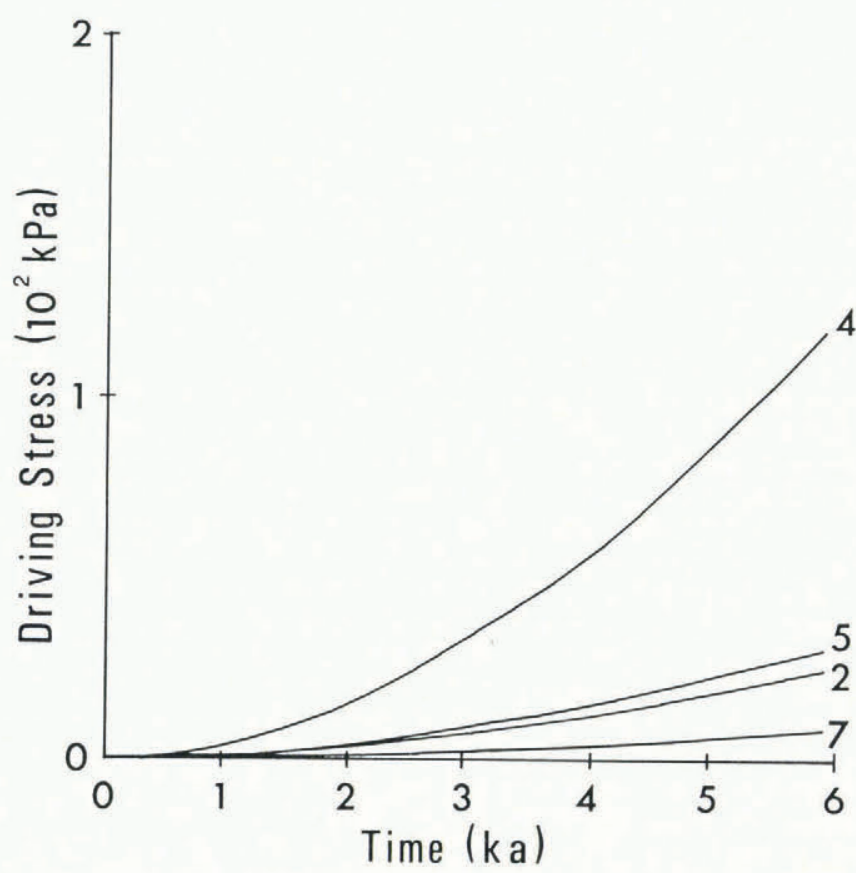

Fig. 4. Area-average driving stress $\left(10^{2} \mathrm{kPa}\right)$ versus time (ka) of the original floating ice-covered region for run numbers 2, 4, 5, and 7 of Table II. Growth of ice is proportional to the accumulation rate $A$ because of its contribution to the $H$ term of Equation (1). The driving stress of grounded ice becomes significant between 20 and $100 \mathrm{kPa}$. 
TABLE II

\begin{tabular}{|c|c|c|c|c|c|c|c|c|}
\hline $\begin{array}{l}\text { Run } \\
\text { No. }\end{array}$ & Purpose & $\begin{array}{c}A \\
\mathrm{~m} \mathrm{a}^{-1}\end{array}$ & $\begin{array}{c}\overline{B^{z}} \\
\mathrm{MN} \mathrm{m}^{-2} \mathrm{~s}^{1 / 3}\end{array}$ & $\begin{array}{c}\text { Sea-level } \\
\mathrm{m}\end{array}$ & $\begin{array}{l}\text { East Antarctic } \\
\quad \text { flux }\end{array}$ & $\begin{array}{c}\text { Basal } \\
\text { temperature } \\
{ }^{\circ} \mathrm{C}\end{array}$ & $\begin{array}{c}\text { Surface } \\
\text { temperature } \\
{ }^{\circ} \mathrm{C}\end{array}$ & $\begin{array}{c}\% \\
\text { grounding }\end{array}$ \\
\hline 1 & Test non-deformable ice & 0.2 & (non-deformable) & 0 & 0 & -1.7 & -20 & 100 \\
\hline 2 & Base run with no flux & 0.2 & 124 & 0 & 0 & -1.7 & -20 & 13 \\
\hline 3 & $\begin{array}{l}\text { Effect of variable } \\
\text { precipitation rate }\end{array}$ & See Fig. 5 & 124 & 0 & 0 & -1.7 & -20 & 11 \\
\hline 4 & $\begin{array}{l}\text { Effect of higher } \\
\text { precipitation rate }\end{array}$ & 0.4 & 124 & 0 & 0 & -1.7 & -20 & 33 \\
\hline 5 & $\begin{array}{l}\text { Effect of lowering } \\
\text { sea-level }\end{array}$ & 0.2 & 124 & -100 & 0 & -1.7 & -20 & 51 \\
\hline 6 & Sea-level lowering & 0.2 & 124 & -50 & 0 & -1.7 & -20 & 33 \\
\hline 7 & $\begin{array}{l}\text { Lower } A \text { value with } \\
\text { lower sea-level }\end{array}$ & 0.1 & 124 & -100 & 0 & -1.7 & -20 & 35 \\
\hline 8 & Larger $\bar{B}^{z}$ on run No. 4 & 0.4 & 150 & 0 & 0 & -1.7 & -20 & 51 \\
\hline 9 & Lower $\bar{B} z$ on run No. 4 & 0.4 & 100 & 0 & 0 & -1.7 & -20 & 16 \\
\hline 10 & $\begin{array}{l}\text { Base run with flux from } \\
\text { East Antarctica }\end{array}$ & 0.2 & 124 & 0 & Present & -1.7 & -20 & 26 \\
\hline 11 & $\begin{array}{l}\text { Effect of flux for run } \\
\text { No. } 7\end{array}$ & 0.1 & 124 & -100 & Present & -1.7 & -20 & 54 \\
\hline 12 & $\begin{array}{l}\text { Effect of flux for run } \\
\text { No. } 5\end{array}$ & 0.2 & 124 & -100 & Present & -1.7 & -20 & 66 \\
\hline
\end{tabular}

the ice shelf, shown in Figure 5, was devised under the constraint that the net mass falling on the entire ice shelf be equivalent to the $0.2 \mathrm{~m} \mathrm{a}^{-1}$ value used in run number 2 . Results of run numbers 2 and 3 vary only slightly from one another, so we conclude that the geographic pattern of snow accumulation is generally irrelevant to the issue of ice-sheet formation.

Denton and Hughes (1981) suggested that West Antarctic marine ice-sheet formation is locked in phase with northern ice-sheet development through their control on eustatic sea-level. We test this hypothesis by performing a number of experiments where sea-level is instantaneously lowered by $50 \mathrm{~m}$ and $100 \mathrm{~m}$ (equivalent to the ice volume of moderately and fully developed glacial periods, respectively). Sea-level is varied in the model by specifying uniformly decreased bed depths beneath the ice shelf.

In the final three runs, we simulate ice flow into the shelf from East Antarctica and from ice which grounds adjacent to East Antarctica by imposing a non-zero ice flux at the grounding line. Flux into West Antarctica was roughly divided into three drainage systems shown in Figure 6. Initial velocities of 500,100 , and $50 \mathrm{~m} \mathrm{a}^{-1}$ were specified at the grounding lines for the basins of Figure 6 with fluxes of $0.05,0.03$, and $0.13 \mathrm{Tm}^{3} \mathrm{a}^{-1}$ (where $\mathrm{T}=10^{12}$ ), respectively. We apply these velocities arbitrarily based on current velocity conditions at ice-sheet/ice-shelf junctions and on the geographic confinement of the border through which the East Antarctic ice is discharged. The $500 \mathrm{~m} \mathrm{a}^{-1}$ discharge velocity, for example, is specified at the narrow border presently occupied by Byrd Glacier, whereas the $50 \mathrm{~m} \mathrm{a}^{-1}$ value is specified along the lengthy boundary extending along the Weddell Sea sector.

The $124 \mathrm{MN} \mathrm{m}^{-2} \mathrm{~s}^{1 / 3} \bar{B} z$ value used for most runs was calculated following the method of Thomas and MacAyeal (1982) for an ice shelf having a linear temperature-depth profile with surface and basal temperatures of $-20^{\circ} \mathrm{C}$ and $-1.7^{\circ} \mathrm{C}$, respectively. Run numbers 8 and 9 investigate the response to raising and lowering this value. These simulations test the influence of: (i) different atmospheric temperatures, (ii) inaccuracy of the assumed linear temperature-depth profile, and (iii) uncertainties in the flow law.

\section{ICE-SHEET FORMATION}

Each simulation was run for 5900 years with a 50 year time step. This was sufficiently long for the ice shelf still remaining after the simulation to attain a steady state, where the absolute values of net mass input and output are equal, except for run numbers 1,10 , and 12 of Table II. Owing to the artificial elimination of ice flow, run number 1 never reaches a steady state. Run numbers 10 and 12, however, were close to a steady-state condition, with mass loss to gain ratios of 0.97 and 0.98 , respectively. The percentage of the original ice-shelf area which had grounded at the end of each run is listed in Table II. Figure 7 shows the percentage of ice shelf remaining for run numbers 2,5 , 10 , and 12 as a function of time.

For the purpose of describing ice-sheet formation, we arbitrarily require $35 \%$ or more of the original floating icecovered region to ground before accepting the run as generating a marine ice sheet. Four reasons for specifying this criterion are: (i) the present grounded part of the West Antarctic ice sheet covers $35 \%$ of our original ice-shelf area, (ii) $35 \%$ grounding is sufficient to form a substantial central grounded core instead of only isolated grounded patches, (iii) the original ice shelf is broken up into a number of separate and unconnected ice shelves, and (iv) this requirement is simple.

To display the range of parameters which permit $35 \%$ grounding, we plot in Figure 8 parameter values of all runs having a $\bar{B}^{Z}$ value of $124 \mathrm{MN} \mathrm{m}^{-2} \mathrm{~s}^{-1 / 3}$ on a coordinate system with axes representing: (i) ice flux from the East Antarctic ice sheet, (ii) surface-accumulation rate, and (iii) sea-level. The boundary separating parameter ranges in which the ice sheet does or does not form in our simulations is plotted as a planar surface.

\section{GROUNDED PATTERN AFTER 5900 YEARS}

The shaded pattern of Figure 9a shows regions of the ice shelf which are presently grounded. Figure $9 \mathrm{~b}-\mathrm{i}$ shows the final grounding of configurations for run numbers 2 , $10,4,6,5,7,11$, and 12 , respectively. The heavy lines 


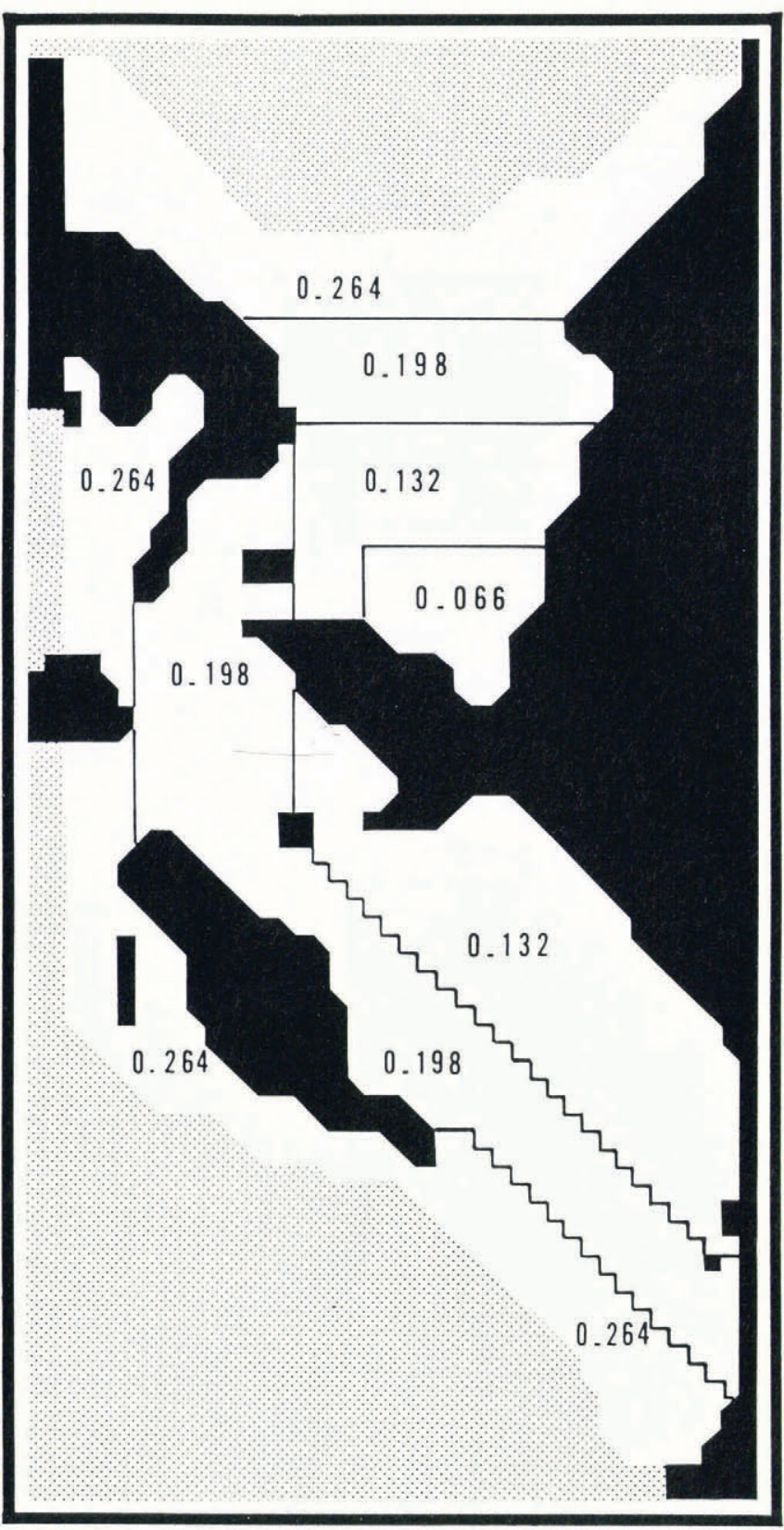

Fig. 5. Precipitation-rate pattern $\left(m^{-1}\right)$ used for testing a variable accumulation rate in run number 3 of Table II. Values were chosen such that the total mass gain over the entire ice shelf per unit time is identical to that of run number 2 of Table II.

enclose regions of the original ice-shelf area which have grounded and the dashed line shows the current ice-front positions for the Ross and Filchner-Ronne Ice Shelves. These figures show that (i) the Ronne Ice Shelf region grounds very easily; (ii) the Filchner Ice Shelf grounds under conditions where the sea-level is lowered and there is ice flux from the East Antarctic ice sheet; and (iii) the Thwaites Glacier and Ross Ice Shelf regions are difficult to ground.

The Ronne Ice Shelf bed is shallow, so grounding is sensitive to changes in sea-level (Fig. $9 \mathrm{e}-\mathrm{g}, \mathrm{h}-\mathrm{i}$ ). Grounding in the region occurs most readily between the Henry and Korff Ice Rises and Berkner Island (Fig. 9c-d). A number of isolated ice rises and rumples exist in this region today (Drewry, 1983, sheet 2). The Filchner Ice Shelf is much harder to ground because of its greater bed depth. Ice influx from the East Antarctic ice sheet and an increase in the accumulation rate by themselves have no influence on the grounding pattern (Fig. 9c-d), and lowering sea-level by itself has only a limited effect (Fig. 9f). A combination of ice flux from the East Antarctic ice sheet and lower sea-

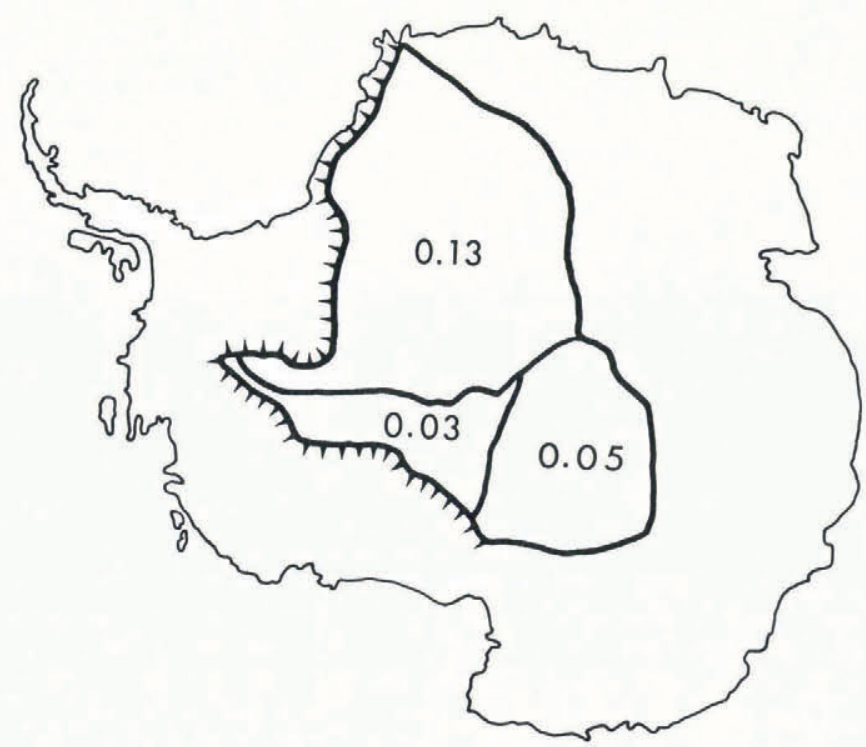

Fig. 6. East Antarctic catchment areas (from sheet 2 of Drewry, 1983) used to calculate the flux of ice into the ice shelf for run numbers 10-12 of Table II. An accumulation rate of $0.1 \mathrm{ma}^{-1}$ over all three basins was assumed. The barbed section represents the region of the boundary where ice initially flows into the shelf. This barbed boundary follows the grounding line as it advances into the ice-shelf domain. The numbers represent the total ice volume $\left(\mathrm{Tm}^{3} \mathrm{a}^{-1}\right)$ flowing into the shelf from each basin.

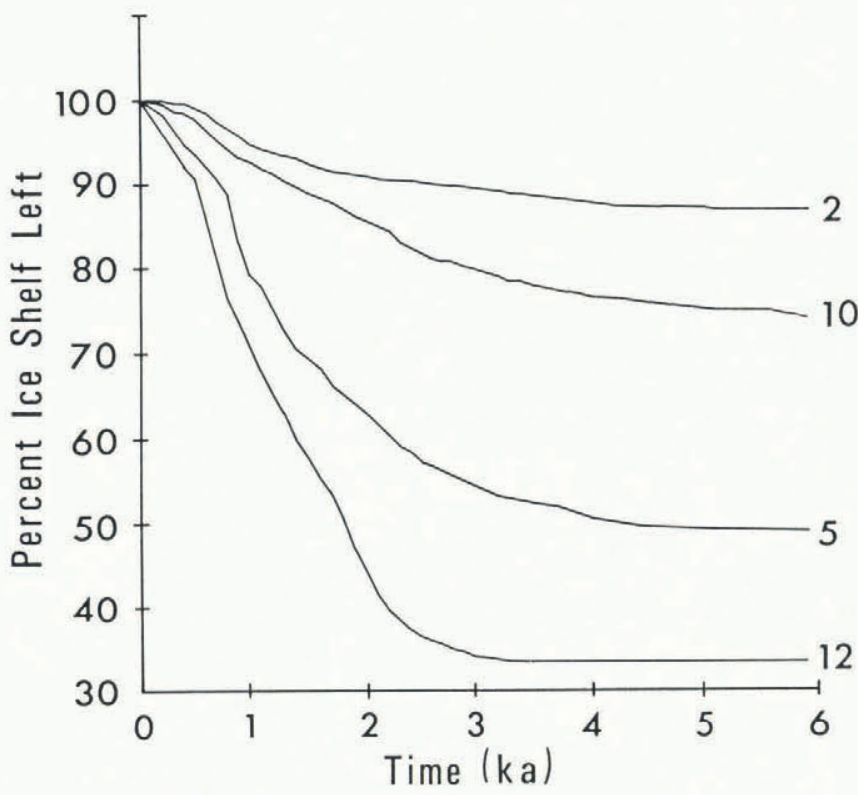

Fig. 7. Graph of percentage of original ice shelf remaining versus time for run numbers $2,5,10$, and 12 of Table II. Sea-level lowering (run numbers 5 and 12) has a greater effect on grounding than ice flux into the ice shelf from the East Antarctic ice sheet (run numbers 2 and 10). Most grounding occurs within the first $2.5 \mathrm{ka}$.

level, however, grounds the entire region, even if the accumulation rate is lowered (Fig. 9h, i).

The area drained by Thwaites Glacier did not ground for any simulations other than run number 1 because of its deep bed and proximity to the calving front. The bed depth allows ice to become very thick and the ice-front proximity promotes a large surface-elevation gradient. These two conditions produce a large driving stress (Equation (6)), which removes ice from the region before it has a chance to ground. We propose that grounding occurs up-stream of Thwaites Glacier today because driving stresses of adjacent 


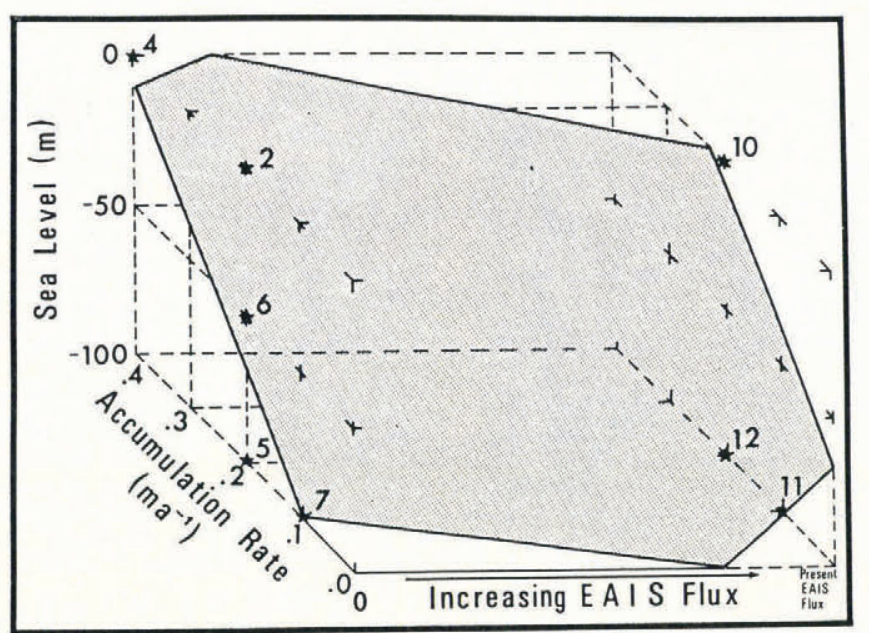

Fig. 8. Planar surface estimation of $35 \%$ ice-shelf grounding on a plot with axes of accumulation rate, sea-level, and East Antarctic ice-sheet flux. The 35\% surface is represented by the shaded pattern. The dashed lines lie within regions where over $35 \%$ grounding occurs. The star symbols with numbers are locations on the plot for the runs listed in Table II. Note that, if present sea-level is not reduced, 35\% grounding occurs only if precipitation is substantially increased above $0.4 \mathrm{~m} \mathrm{a}^{-1}$ and input flux from the East Antarctic ice sheet remains at or near present-day levels. If sea-level falls by $100 \mathrm{~m}$, however, $35 \%$ grounding will occur unless the precipitation rate is decreased and input flux from the East Antarctic ice sheet is near zero. grounded ice have flushed large amounts of ice into previously ungrounded regions.

The Ross Ice Shelf is hard to ground because of its moderately large bed depths and long ice-shelf front. Glacial geologic studies (Stuiver and others, 1981) and seacore sedimentological analyses (Kellogg and others, 1979), however, indicate ice was grounded in the Ross Sea basin to the continental shelf $18 \mathrm{ka} \mathrm{BP}$. This grounding must have occurred by processes similar to those which we speculate caused grounding up-stream of Thwaites Glacier.

\section{ICE-SHELF DEVELOPMENT THROUGH TIME}

Histories of mass balance, fraction of original ice-shelf front remaining, average thickness, volume, average velocity, and fraction of original ice shelf remaining are presented as functions of time in Figures $10-14$ and Figure 7, respectively, for run numbers $2,5,10$, and 12 . These runs were chosen because they represent varying degrees of final ice-shelf grounding.

As demonstrated by the histories of area-average thickness and ice volume, ice-shelf build-up generally proceeds rapidly through the first 1500 years. Following this, the build-up slows as steady-state conditions are approached. From roughly 1500 to 3000 years, average ice-shelf thickness and volume decrease for run number 12. This decrease can be attributed to selective removal of the thickest parts of the ice shelf. Smaller humps and irregularities of the curves result from small-scale regional grounding and from thickening of ice-shelf segments cut off from the ocean by surrounding grounded ice.

The leaky bucket analogy of marine ice-sheet formation
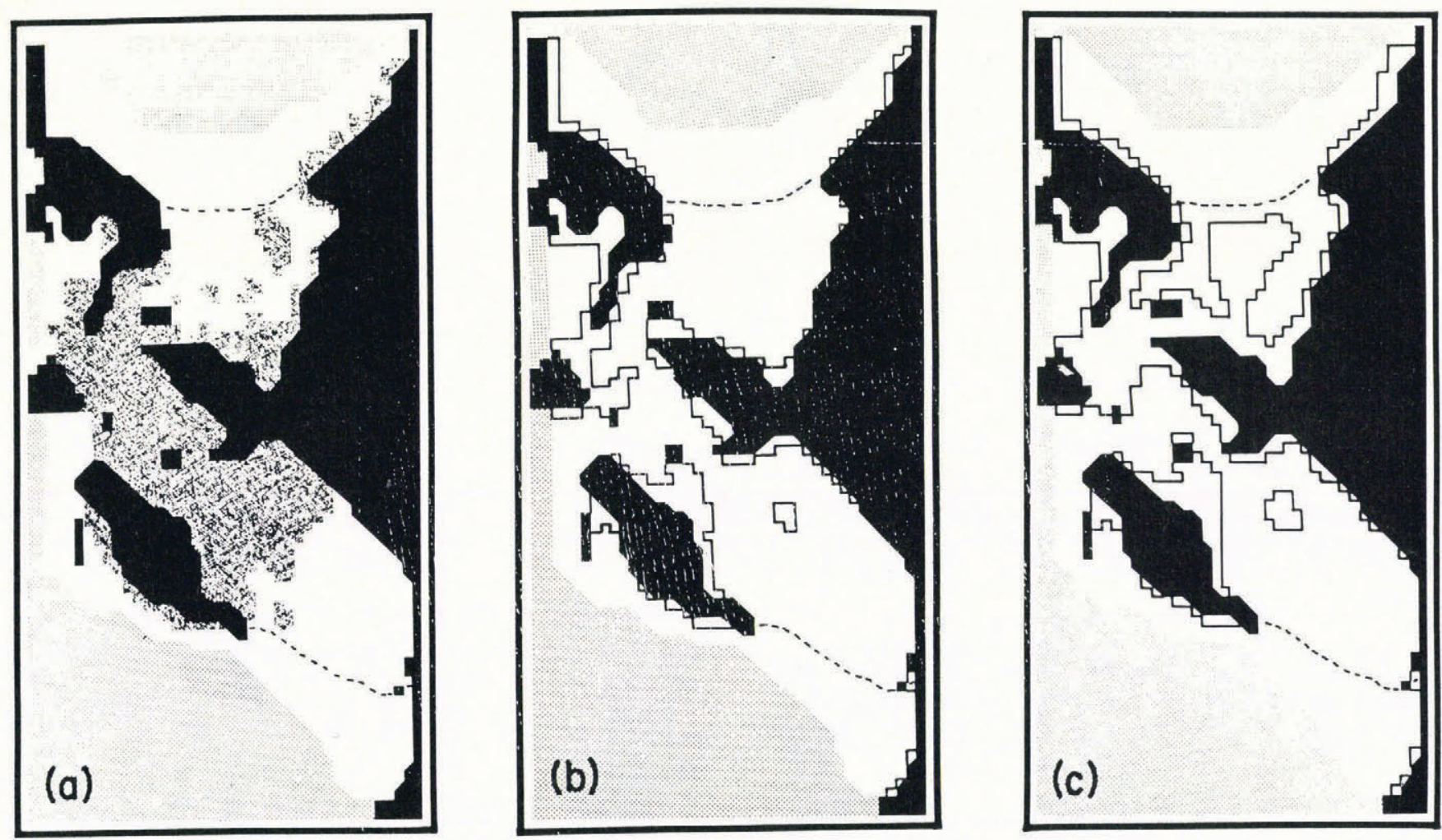

Fig. 9. Final areal coverages of grounded ice cover for run numbers 2, 10, 4, 6, 5, 7, 11, and 12 of Table II. The dashed lines denote the current seaward ice front of the Ross and Filchner-Ronne Ice Shelves. In Figure $9 b-i$, the heavy lines enclose regions of the original floating ice cover that have grounded.

(a) The shaded region represents areas of the initial ice-shelf configuration that are presently covered by grounded ice. This is to be used for comparisons with the grounded patterns in Figure $9 b-i$.

(b) Final configuration for run number 2. This run simulates how West Antarctic development would proceed if present-day environmental conditions ( $A=0.2 \mathrm{ma}^{-1}$, present sea-level) existed with the constraint that no ice flows into the region from the East Antarctic ice sheet. Very little grounding occurs.

(c) Final configuration for run number 10. Specifications for this run are the same as those for run number 2, except that some East Antarctic ice is fluxed into the West Antarctic. Ice grounding occurs up-stream of Rutford Ice Stream and between Berkner Island and Henry and Korff Ice Rises. Very little additional grounding occurs in the Ross Sea region because the amount of flux input is insignificant along the entire coast except at Byrd Glacier. Byrd Glacier is close enough to the seaward ice front so that its input can be removed from the system without difficulty. 

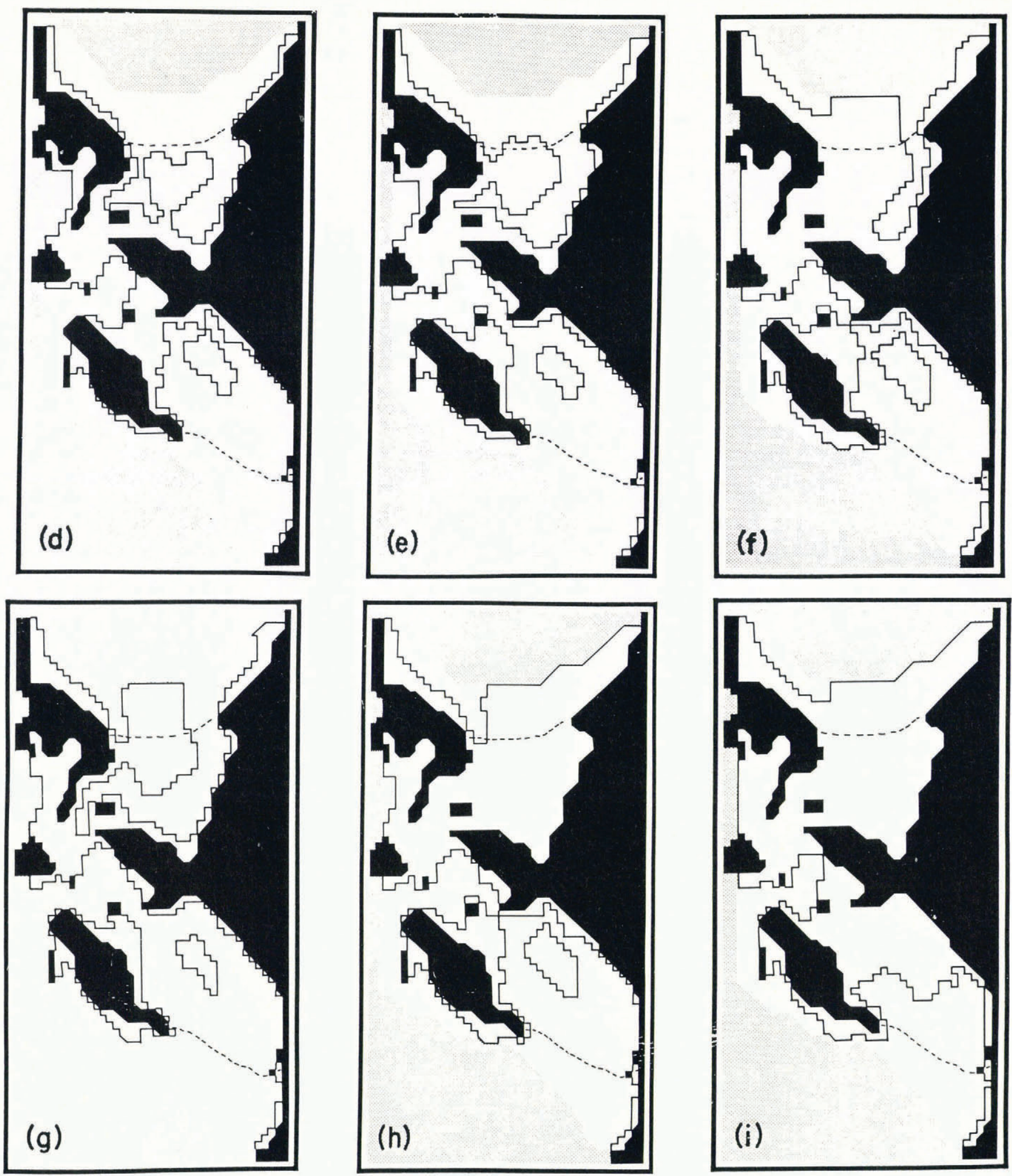

(d) Final configuration for run number 4. Ice flux from the East Antarctic ice sheet is once more set to zero and the precipitation rate is increased to $0.4 \mathrm{~m} \mathrm{a}^{-1}$. The increased precipitation allows ice to ground in interior regions and between Berkner Island and Henry and Korff Ice Rises.

(e) Final configuration for run number 6. The precipitation rate is decreased again to a value of $0.2 \mathrm{~m} \mathrm{a}^{-1}$ and sea-level is lowered by $50 \mathrm{~m}$. Substantial grounding occurs over shallow regions of the bed (Ronne Ice Shelf region and over an isolated region near the present grounding line of the Ross Ice Shelf). The grounding of ice in the Ronne Ice Shelf region hinders ice flow up-stream of Rutford and Evans Ice Streams and eventually causes grounding in these regions.

(f) Final configuration for run number 5. Sea-level is lowered by $100 \mathrm{~m}$. Results are similar to Figure $9 e$ but strongly amplified. The bed beneath the Filchner Ice Shelf is deep enough so that this additional sea-level drop has little effect on it.

(g) Final configuration for run number 7. The precipitation rate is lowered to $0.1 \mathrm{ma}^{-1}$. Sea-level is lowered $100 \mathrm{~m}$. The grounding pattern is similar to Figure $9 f$, but the reduced mass input from precipitation allows a larger region down-stream from Rutford and Evans Ice Streams to remain ungrounded and drain through the Filchner Ice Shelf. Less ice grounding also occurs up-stream of the present Ross Ice Shelf grounding line.

(h) Final configuration for run number 11. Ice flux is allowed from the East Antarctic ice sheet. Sea-level is lowered by $100 \mathrm{~m}$. This is sufficient to ground completely the Filchner Ice Shelf. Little additional grounding occurs in the Ross Sea region for reasons mentioned in Figure $9 c$.

(i) Final configuration for run number 12. Parameter values are the same as in run number 11, except the precipitation rate is increased to $0.2 \mathrm{ma}^{-1}$. Ice grounding occurs over all regions except the Ross Sea region and up-stream of Thwaites Glacier. Grounding over these two areas will probably occur

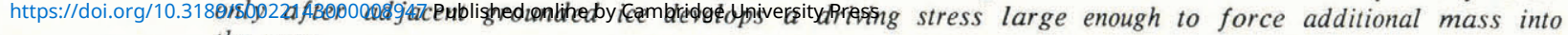
the area. 


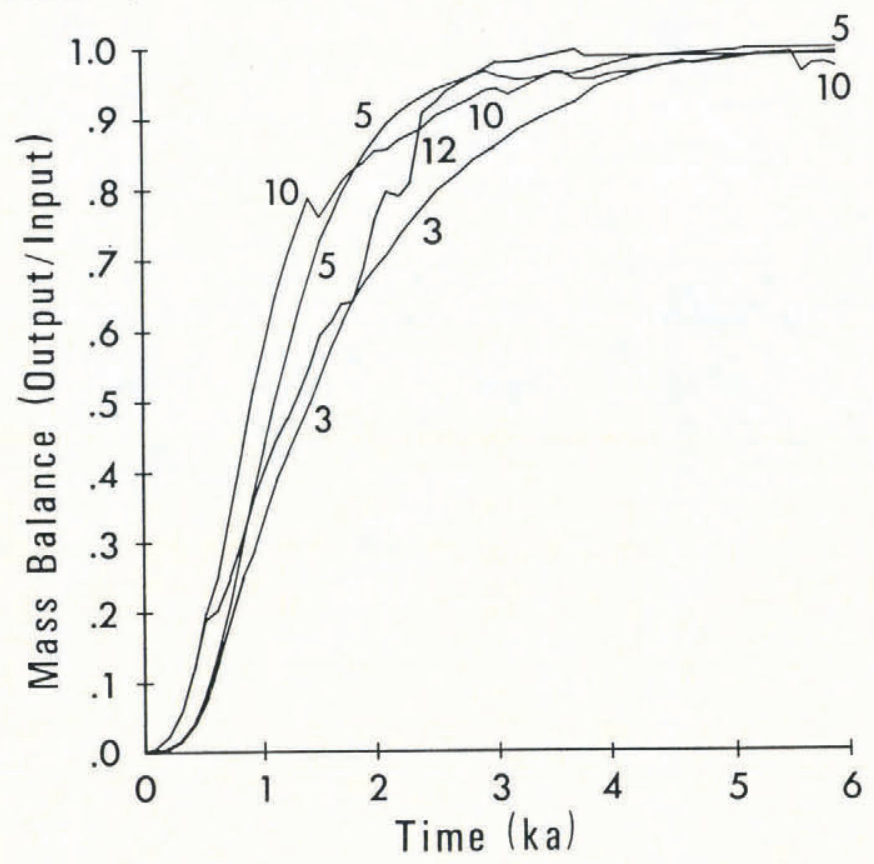

Fig. 10. The mass balance (ratio of mass loss to mass gain) of the floating part of the ice cover at time $t$ for run numbers $3,5,10$, and 12 of Table II. The ratio strongly increases for the first $2 \mathrm{ka}$ as the seaward ice-front velocity develops. After this time, the values approach a steady state of mass balance. Small-scale humps, especially prevalent in run numbers 10 and 12 , result from adjustments of the floating-ice system to localized grounding.

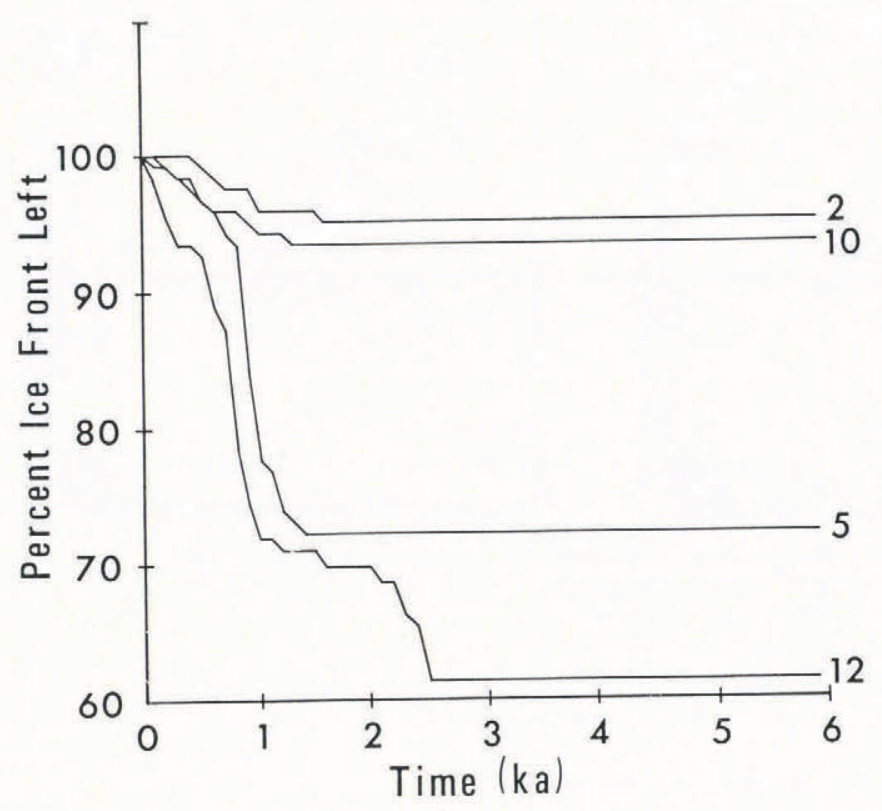

Fig. 11. Plot of the percentage remaining of the original seaward ice-shelf front at time $t$ for run numbers 2, 5 , 10, and 12 of Table II. The amount of seaward ice-front grounding is proportional to the total amount of grounding (Fig. 7) because ice-front grounding reduces the length through which ice calving can occur. The amount of seaward ice-front grounding is more strongly influenced by lowering sea-level than by having an ice flux from the East Antarctic ice-sheet region.

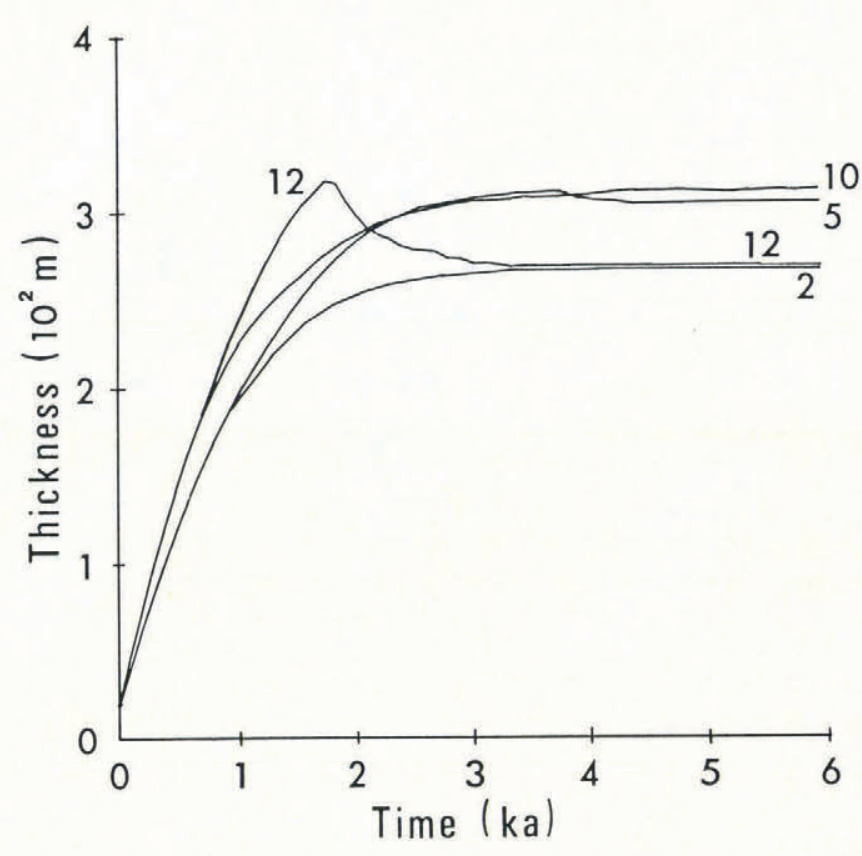

Fig. 12. Average ice thickness for the floating ice cover as a function of time for run numbers 2, 5, 10, and 12 of Table II. The thickness increases rapidly for the first $1 \mathrm{ka}$ before ice velocities have developed and then levels off. The average floating-ice thickness for run number 12 decreases during the time period from 1 to $2 \mathrm{ka}$ as thick interior regions ground.

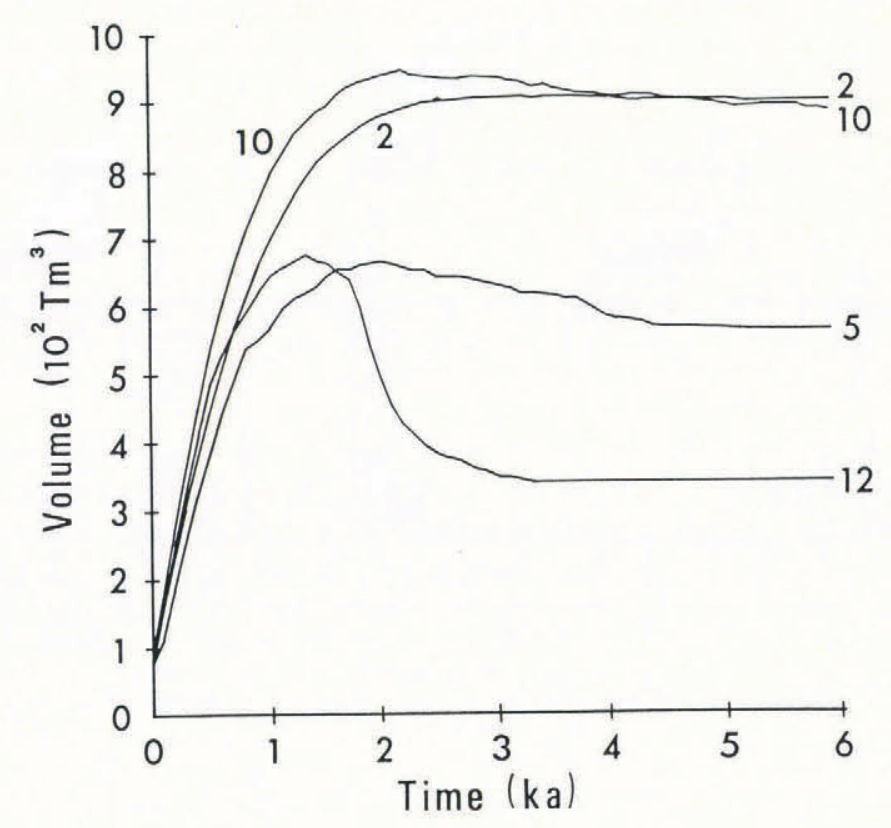

Fig. 13. Total volume of floating-ice cover as a function of time for run numbers $2,5,10$, and 12 of Table II. The ice volume increases rapidly over the first $1 \mathrm{ka}$ because (i) the seaward ice-front velocity is not large enough to discharge a significant mass of ice into the ocean and (ii) the ice is still not thick enough to ground over many regions. The floating-ice volume decreases from 1 to $3 \mathrm{ka}$ for run number 12 as many thick parts begin to ground. 


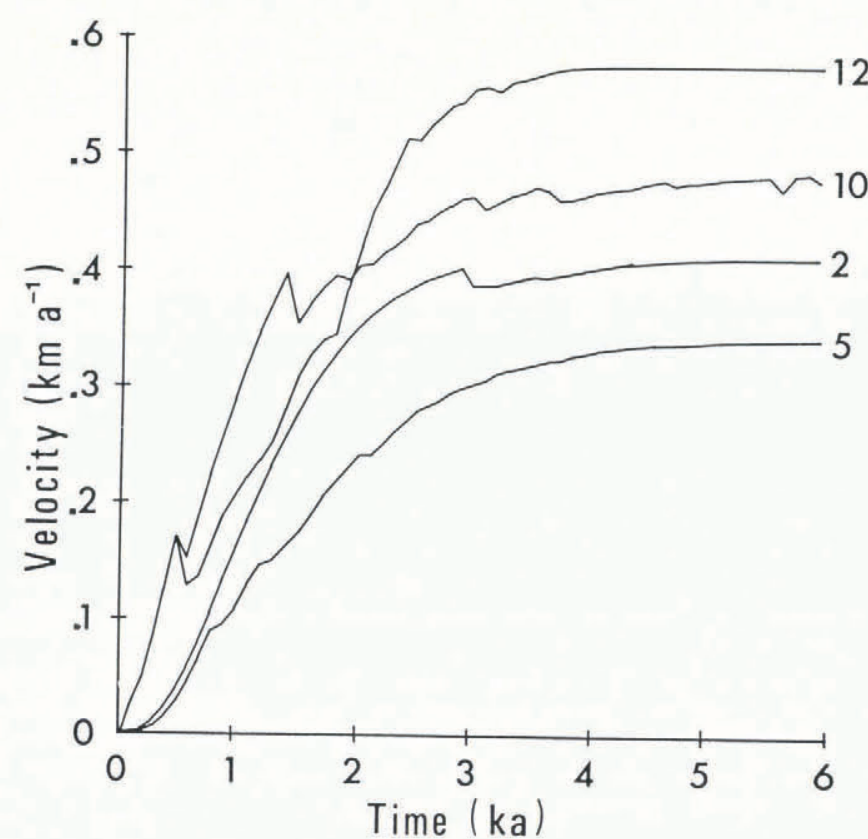

Fig. 14. Average ice-shelf velocity over time for run numbers 2. 5, 10, and 12 of Table II. The velocity increases rapidly over the first $2 \mathrm{ka}$ and then levels off as a mass-balance condition is approached. Minor humps, especially prevelant in run numbers 10 and 12 , result from adjustments to localized grounding of ice. The larger humps result from ice grounding in central ice-shelf regions which are not adjacent to other grounded areas.

described earlier is clearly evident in the histories of iceshelf area and ice-front length. As the ice-shelf thickness builds up, and the ratio of net ice discharge to accumulation increases, the seaward ice-front length within the West Antarctic basin is shortened. This is accomplished by ice-shelf grounding in gaps between islands which enclose the West Antarctic basin and at isolated sea-bed bumps in the Ross and Weddell Seas. For those runs which are successful in forming a marine ice sheet, the ice-front length is shortened by a substantial amount, up to $30-40 \%$. This confirms the tendency for ice-shelf grounding to seal leaks that otherwise would prevent build-up of a marine ice sheet.

\section{POSSIBLE SCENARIO FOR THE WEST ANTARCTIC ICE- SHEET DEVELOPMENT}

We propose the following scenario of West Antarctic ice-sheet development based on our numerical simulation results. Ice-sheet development begins after an interglacial period where grounded ice has collapsed in regions below sea-level and isostatic adjustment of the bed has occurred, as in Figures 1 and 2.

At the early stages of the glacial period, before enough ice has accumulated in the Northern Hemisphere to lower significantly sea-level, an ice cover over West Antarctica similar to that of Figure 9c develops, with limited grounding in: (i) the central sector except up-stream of Thwaites Glacier, (ii) the Ronne Ice Shelf between Henry and Korff Ice Rises and Berkner Island, and (iii) the isolated shallow bed region up-stream of the present Ross Ice Shelf grounding line.

As sea-level falls with Northern Hemisphere ice buildup, additional grounding occurs over the Ronne Ice Shelf and in the central sector, as shown in Figure 9e. When the Northern Hemisphere's ice sheets are near their maximum size, a grounded distribution similar to that of Figure 9i exists. Eventually, as the grounded parts develop significant driving stresses, regions up-stream of Thwaites Glacier and the Ross Ice Shelf also ground by the flux of grounded ice into the ice shelf.

\section{SUMMARY}

Our results address answers to several questions raised concerning: (i) whether the West Antarctic ice sheet could have re-established itself if it collapsed during the Sangamon Interglacial $125 \mathrm{ka}$ BP (Mercer, 1968), (ii) what climatic conditions will be needed and how long it will take the West Antarctic ice sheet to re-establish itself if it collapses within the next millennium from atmospheric trace gas and $\mathrm{CO}_{2}$ increases (Mercer, 1978; Manabe and Stouffer, 1979; Ramanathan and others, 1979), and (iii) the relative importances of ice-shelf thickening (Wexler, 1961; Hughes, 1982) and grounded ice flux (Bentley and Ostenso, 1961) in initiating the West Antarctic ice sheet.

For the first two questions, our study has shown that a precursor to the West Antarctic ice sheet can form within several thousand years under realistic environmental conditions once sea-level is lowered in association with a Northern Hemisphere glaciation. Our result is consistent with the view that glacial events in the Southern Hemisphere are phase-locked with those of the Northern Hemisphere through eustatic sea-level (Hollin, 1962). Flux of ice from the East Antarctic ice sheet and the accumulation rate are also significant factors, but not as important as sea-level changes.

In the third case, our results shows that all parts of the West Antarctic ice sheet can form through ice-shelf thickening alone except up-stream of Thwaites Glacier and in the Ross Sea region. Grounding up-stream of Thwaites Glacier and in the Ross Sea region occurs only after neighboring grounded ice has developed a driving stress large enough to force more ice mass into these areas. We are currently refining our model so that it can treat groundedice dynamics and isostatic adjustments of the bed.

\section{ACKNOWLEDGEMENTS}

This work was supported by U.S. National Science Foundation grant DPP-8401016. We thank K. Bryan, Jr, M.M. Monaghan, R.G. Grumbine, A. Ziegler, T.J. Hughes, G.H. Denton, T.B. Kellogg, B. Stauffer, and an anonymous referee for helpful suggestions and criticisms throughout the span of this project. Finally, we wish to acknowledge and dedicate this paper to John Mercer, who pioneered the study of West Antarctic ice-sheet stability.

\section{REFERENCES}

Bentley, C.R., and Ostenso, N.A. 1961. Glacial and subglacial topography of West Antarctica. Journal of Glaciology, Vol. 3, No. 29, p. 882-911.

Budd, W.F., and others. 1987. Modelling the response of the West Antarctic ice sheet to a climatic warming, by W.F. Budd, B.J. McInnes, D. Jenssen, and I.N. Smith. (In Veen, C.J. van der, and Oerlemans, J., eds. Dynamics of the West Antarctic Ice Sheet. Proceedings of a Workshop held in Utrecht, May 6-8, 1985. Dordrecht, etc., D. Reidel Publishing Company, p. 321-58.)

Denton, G., and Hughes, T.J. 1981. The Arctic ice sheet: an outrageous hypothesis. (In Denton, G., and Hughes, T.J., eds. The last great ice sheets. New York, Wiley-Interscience, p. 437-67.)

Drewry, D.J., ed. 1983. Antarctica: glaciological and geophysical folio. Cambridge, University of Cambridge. Scott Polar Research Institute.

Giovinetto, M.B., and Bentley, C.R. 1985. Surface balance in ice drainage systems of Antarctica. Antarctic Journal of the United States, Vol. 20, No. 4, p. 6-13.

Hollin, J.T. 1962. On the glacial history of Antarctica. Journal of Glaciology, Vol. 4, No. 32, p. 173-95.

Hughes, T.J. 1982. Did the West Antarctic ice sheet create the East Antarctic ice sheet? Annals of Glaciology, Vol. 3, p. $138-45$.

Hutter, K. 1983. Theoretical glaciology; material science of ice and the mechanics of glaciers and ice sheets. Dordrecht, etc., D. Reidel Publishing Company/Tokyo, Terra Scientific Publishing Company. 
Kellogg, T.B., and others. 1979. Late Quaternary extent of the West Antarctic ice sheet: new evidence from Ross Sea cores, by T.B. Kellogg, R.S. Truesdale, and L.E. Osterman. Geology, Vol. 7, p. 249-53.

Lapidus, L., and Pinder, G.F. 1982. Numerical solution of partial differential equations in science and engineering. New York, John Wiley \& Sons.

Lindstrom, D., and MacAyeal, D.R. 1986. Paleoclimatic constraints on the maintenance of possible ice-shelf cover in the Norwegian and Greenland seas. Paleoceanography, Vol. 1, p. 313-37.

Manabe, S., and Stouffer, R.J. 1979. A $\mathrm{CO}_{2}$-climate sensitivity study with a mathematical model of the global climate. Nature, Vol. 282, No. 5738, p. 491-93.

Mercer, J.H. 1968. Antarctic ice and Sangamon sea level. Union de Géodésie et Géophysique Internationale. Association Internationale d'Hydrologie Scientifique. Assemblée Générale de Berne, 25 sept.-7 oct. 1967. [Commission de Neiges et Glaces.] Rapports et discussions, p. 217-25. (Publication No. 79 de l'Association Internationale d'Hydrologie Scientifique.)

Mercer, J.H. 1978. West Antarctic ice sheet and $\mathrm{CO}_{2}$ greenhouse effect: a threat of disaster. Nature, Vol. 271, No. 5643, p. $321-25$
Muszynski, I., and Birchfield, G.E. 1987. A coupled marine ice-stream-ice shelf-model. Journal of Glaciology, Vol. 33, No. 113, p. 3-15.

Ramanathan, V., and others. 1979. Increased atmospheric $\mathrm{CO}_{2}$ : zonal and seasonal estimates of the effect on the radiation energy balance and surface temperature, by $\mathrm{V}$. Ramanathan, M.S. Lian, and R.D. Cess. Journal of Geophysical Research, Vol. 84, No. C8, p. 4949-58.

Stuiver, M., and others. 1981. History of the marine ice sheet in West Antarctica during the last glaciation: a working hypothesis, by M. Stuiver, G.H. Denton, T.J. Hughes, and J.L. Fastook. (In Denton, G.H., and Hughes, T.J., eds. The last great ice sheets. New York, Wiley-Interscience, p. 319-436.)

Thomas, R.H., and MacAyeal, D.R. 1982. Derived characteristics of the Ross Ice Shelf, Antarctica. Journal of Glaciology, Vol. 28, No. 100, p. 397-412.

Wexler, H. 1961. Growth and thermal structure of the deep ice in Byrd Land, Antarctica. Journal of Glaciology, Vol 3, No. 30, p. 1075-87.

Whillans, I.M. 1987. Force budget of ice sheets. (In Veen, C.J. van der, and Oerlemans, J., eds. Dynamics of the West Antarctic Ice Sheet. Proceedings of a Workshop held in Utrecht, May 6-8, 1985. Dordrecht, etc., D. Reidel Publishing Company, p. 17-36.) 